\title{
Effect of continuous positive airway pressure on fluid absorption among patients with pleural effusion due to tuberculosis
}

\section{Efeito da pressão positiva nas vias aéreas sobre a absorção do derrame pleural em pacientes devido à tuberculose}

Juliana F. Oliveira', Fernanda C. Q. Mello², Rosana S. Rodrigues², Ana L. Boechat² ${ }^{2}$ Marcus B. Conde², Sara L. S. Menezes ${ }^{1,2}$

\begin{abstract}
Background: Tuberculosis (TB) remains as an important public health problem worldwide. The most common type is pulmonary TB, and the most prevalent form of extra-pulmonary disease among HIV-negative patients is pleural disease. Objective: The objective of the present study was to determine the effect of continuous positive airway pressure (CPAP) on fluid absorption among patients with pleural effusion due to TB. Methods: Twenty patients were randomized into two groups. The interventional group $(n=10)$ received CPAP three times a week during the initial four weeks of anti-TB treatment, and the control group $(n=10)$ received anti-TB drugs only. The primary endpoint was the volume of pleural fluid after four weeks of treatment. Both groups were submitted to thoracic computed tomography using threedimensional image reconstruction. The Mann-Whitney test for independent samples and the Wilcoxon paired samples test were used for statistical analysis. The normal distribution samples were analyzed using the unpaired $t$ test. Results: The reduction of pleural effusion volume was significantly greater in the intervention group ( $83.5 \% \pm S D$ 3.6) than in the control group $(36.9 \% \pm S D 2.9 ; p<0.001)$, and the final dyspnea index was lower in the Intervention group than in the control group $(p=0.002)$. Conclusion: Our findings indicate that CPAP during the first month of TB treatment accelerates the absorption of pleural effusion, however, additional studies are needed to confirm these findings and evaluate the impact of CPAP on pleural sequelae after the end of anti-TB treatment.
\end{abstract}

Article registered in the Clinical Trials under the number NCT00560521.

Key words: physical therapy; pleural effusion; continuous positive airway pressure; pleural tuberculosis.

\section{Resumo}

Contextualização: A tuberculose (TB) permanece como um importante problema de saúde pública no mundo. A forma mais comum de apresentação é a pulmonar e, em pacientes soronegativos, a forma de doença extrapulmonar mais prevalente é a pleural. Objetivo: O objetivo deste estudo foi determinar o efeito da pressão positiva contínua em vias aéreas (CPAP) na absorção do derrame pleural em pacientes com tuberculose. Métodos: Vinte pacientes foram randomizados em dois grupos. O grupo intervenção $(n=10)$ recebeu CPAP três vezes por semana durante as quatro primeiras semanas do tratamento anti-TB, e o grupo controle $(n=10)$ recebeu somente droga anti-TB. O ponto final de avaliação foi o volume de líquido pleural após quatro semanas de tratamento. Ambos os grupos foram submetidos à tomografia computadorizada, usando a reconstrução tridimensional (3D) da imagem. A análise estatística foi realizada por meio do teste de Mann-Whitney para amostras independentes e Wilcoxon para amostras pareadas, e as que apresentaram distribuição normal foram analisadas por meio do teste $t$ de Student não pareado. Resultados: A redução do volume de derrame pleural foi significativamente maior no grupo intervenção $(83,5 \% \pm D P 3,6)$ que no grupo controle $(36,9 \% \pm D P 2,9)(p<0,001)$, e o índice de dispnéia final foi menor no grupo CPAP que no grupo controle $(p=0,002)$. Conclusão: Tais achados indicam que a CPAP, durante o primeiro mês de tratamento anti-TB, acelera a absorção do derrame pleural, no entanto estudos adicionais são necessários para confirmar estes achados e avaliar o impacto da CPAP na sequela pleural após o término do tratamento anti-TB. Artigo registrado no Clinical Trials sob o número NCT00560521.

Palavras-chave: fisioterapia; derrame pleural; pressão positiva contínua em vias aéreas; tuberculose pleural.

Received: 10/11/2008 - Revised: 06/03/2009 - Accepted: 15/04/2009 


\section{Introduction $: \therefore$.}

For over a decade the World Health Organization (WHO) has declared tuberculosis (TB) a global emergency. According to the 2004 WHO estimate, two billion people are infected by Mycobacterium tuberculosis worldwide. Among these, eight million will develop the disease and 2 million will die each year ${ }^{1}$.

In the city of Rio de Janeiro (Brazil), there were 9789 new cases of TB reported in 2004, with $15 \%$ of cases exhibiting extra-pulmonary disease, $46 \%$ of which were pleural $\mathrm{TB}^{2}$. Pleural TB is the consequence of a delayed-type hypersensitivity reaction in response to the rupture of a subpleural focus of Mycobacterium tuberculosis infection ${ }^{3}$. The main clinical finding is pleural effusion and its diagnosis should be considered in any patient with an exudative effusion ${ }^{4}$. Although small/ moderate in size in most cases, among those patients with larger volume, a restrictive ventilatory functional disturbance can occur with moderate reduction in pulmonary volume and compliance, as well as variations in gas exchange, reduction in oxygen partial pressure $\left(\mathrm{PaO}_{2}\right)$ and increase in carbon dioxide partial pressure $\left(\mathrm{PaCO}_{2}\right)^{5,6}$. A clinically relevant factor in the treatment of patients with TB-related pleural effusion is the degree of respiratory discomfort ${ }^{7}$.

Brazil's national TB program recommends standard treatment with rifampin and isoniazid for six months, in addition to pyrazinamide during the first two months of treatment for all cases of pleural TB with the following aims: (1) to prevent the subsequent development of active pulmonary TB, (2) to relieve symptoms and (3) to prevent pleural sequelae (pleural fibrosis) ${ }^{8}$. Despite the lack of published evidence regarding the effectiveness of continuous positive airway pressure (CPAP) on pleural effusion absorption during pleural TB treatment, it has been used as an adjuvant treatment ${ }^{9,10}$. The aim of the present study was to determine the efficacy of CPAP on fluid absorption among patients with pleural effusion due to TB.

\section{Methods : : :}

The present study prospectively recruited patients age 18 years or older with a confirmed diagnosis of pleural TB effusion between December 1, 2005 and March 31, 2007. All patients were initially evaluated at two hospitals (Hospital Cardoso Fontes and Hospital Universitário Antonio Pedro in Rio de Janeiro, Brazil). At both hospitals, patients underwent a chest radiograph with posterior, anterior and lateral decubitus views, thoracocentesis and pleural biopsy with a Cope needle. Pleural fluid and two pleural fragments were stained with Ziehl-Neelsen stain and cultured in Lowenstein-Jensen medium. Three other fragments were stained with hematoxylin and eosin. The volume of pleural fluid withdrawn ranged from 50 to $80 \mathrm{~mL}$. Diagnosis of pleural TB was based on the growth of Mycobacterium tuberculosis in pleural fluid and/or pleural fragment or the presence of granulomas in the histopathology study of the pleural fragment.

Patients with confirmed diagnosis of pleural TB were invited to take part in the study. Before initiating anti-TB treatment, subjects who signed the informed consent form were randomized to an intervention group or to a control group using computer generated blocks in groups of two. The mean age of the control group was $39.5 \pm 17.63$ while the intervention group was $42.5 \pm 13.53$. Subjects from both groups were submitted to a thoracic Computed Tomography (CT) scan at Hospital Universitário Clementino Fraga Filho (HUCFF) of Universidade Federal do Rio de Janeiro, Brazil (UFRJ) before starting treatment and after four weeks of treatment. Patients assigned to the intervention group received CPAP in addition to standard anti-TB treatment. CPAP was carried out by a single physical therapist, three times a week, using positive end-expiratory pressure (PEEP) of $10 \mathrm{cmH}_{2} \mathrm{O}$ for 30 minutes through a flow generator (CriticalMed ${ }^{\circledR}$, Rio de Janeiro, Brazil) and a silicone face mask (Dinatech ${ }^{\circledR}$ ), in a sitting position for four weeks, respiratory rate, arterial blood pressure, oxygen saturation and heart rate were measured at minute 15 and immediately after application. Dyspnea was evaluated before and after treatment through a Modified Borg Scale ${ }^{11}$. Both groups received standard TB treatment with rifampin and isoniazid for six months, with the addition of pyrazinamide during the first two months of treatment ${ }^{3}$. Anti-TB drug ingestion was monitored in both groups through daily phone contact. Furthermore, a pill count was carried out by the nurse technician who supplied the patients with the tablets weekly.

Two radiologists specifically trained for the present study were blinded to group allocation and used a technique validated for this purpose $\mathrm{e}^{12}$. The radiologists analyzed the volume of pleural fluid through a thoracic CT scan using a dual-slice helical scanner (General Electric Medical Systems, Hispeed Fx/i model 2263139-127) with axial plane slices of $1 \mathrm{~mm}$ collimation, in deep inspiration, $10 \mathrm{~mm}$ feed, 5 slices, pitch $2, \mathrm{kV} 130$ and mAs 60, filter $41 \mathrm{~mm}$ for mediastinal and $70 \mathrm{~mm}$ for pulmonary parenchyma. The hypo dense area with fluid was contoured (Figure 1A), and the images generated were post-processed (1B and 1C) using Somavision version 6.1 Workstation for three-dimensional (3D) reconstruction and Somavision version 10.2 for volume inspection. The primary endpoint of the study was the volume of pleural fluid after four weeks of treatment. The CT scans were examined in the mediastinal window with the 
following parameters: $450 \mathrm{HU}$ (Hounsfield units; window) and $20 \mathrm{HU}$ (level). Patients were excluded from the study if they did not take the standard anti-TB medications for 2 days or if they did not come to one of the CPAP sessions or radiological evaluations.

The variables that did not present normal distribution and/or homogeneity of variances were analyzed with the Mann-Whitney test for independent samples and the Wilcoxon test for paired samples. Those presenting normal distribution were analyzed with the unpaired $t$ test. Differences were considered significant if $\mathrm{p} \leq 0.05$. The sample size was based on type I error with alpha $5 \%$, power $80 \%$ and estimate difference of $30 \%$. It was calculated through the following equation $\mathrm{n}=\left[\mathrm{Z}_{\alpha} \sqrt{ } \mathrm{P}_{0}\left(1-\mathrm{P}_{0}\right)+\mathrm{Z}_{\beta} \sqrt{ } \mathrm{P}_{\mathrm{a}}\left(1-\mathrm{P}_{\mathrm{a}}\right)\right]^{2} /\left(\mathrm{P}_{0}-\mathrm{P}_{\mathrm{a}}\right)^{2}$.

Informed written consent was obtained from all participants, and the study was approved by the Institutional Regulatory Board (IRB) of Hospital Universitário Clementino Fraga Filho of Universidade Federal do Rio de Janeiro under number 033/04.

\section{Results $:: \therefore$}

Twenty patients were screened and invited to take part in the study. Twenty patients were included and had endpoints evaluated. All strains were tested and were non-resistant to rifampin and isoniazid. Our laboratory does not perform sensitivity testing for pyrazinamide. No patients were excluded from the study. The baseline characteristics of the study sample are shown in Table 1. The mean age and sex were nearly identical in the two groups. There was no significant difference in the location of the pleural effusion and size. There were no adverse effects associated with the use of CPAP.

Table 2 shows that the relative variation between the initial and final (after 4 weeks of treatment) pleural fluid volume was significantly greater in the intervention group (83.5\% \pm 3.6$)$ than in the control group $(36.9 \% \pm 2.9 ; \mathrm{p}<0.001)$ suggesting that CPAP accelerated the speed of fluid absorption. At the beginning of the study, the dyspnea index did not differ between groups (Table 1), but after 4 weeks of treatment it was significantly lower in the intervention group, with a median of $0(0-1)$, than in the control group, with a median of $2.0(0-2 ; p=0.002)$. There was no significant difference between the groups regarding cardiac and respiratory frequency values, arterial pressure and peripheral oxygen saturation $\left(\mathrm{SpO}_{2}\right)$.

Figure 2 shows the reconstruction of the initial pleural effusion volume in 3D. Figure 3, shows the final volume of a patient from the CPAP group. Figure 4 is a reconstruction of the initial pleural effusion volume in 3D, and Figure 5, the final volume of a patient from the control group.

\section{Discussion $: \because$.}

Our study showed a significant reduction in pleural effusion size in the intervention group (83.5\%) after 4 weeks of treatment compared with the control group (36.9\% \pm SD 2.9; $\mathrm{p}<0.001$ ). Fifty percent of patients with pleural TB develop pleural thickening one year after treatment with anti-TB drugs, and the prevention of pleural fibrosis is one of the goals of TB treatment ${ }^{13}$. The faster reduction in pleural effusion volume might be associated with a lower rate of pleural fibrosis ${ }^{14}$. In fact, a recent randomized controlled study with 52 patients showed that the intrapleural administration of a hyaluronatebased gel (HAbg) resulted in significantly faster fluid absorption and significantly less pleural thickening at three months ${ }^{15}$. Although respiratory physical therapy in patients with pleural

Table 1. Baseline characteristics.

\begin{tabular}{lccc}
\hline & $\begin{array}{c}\text { Control group } \\
(\mathrm{n}=10)\end{array}$ & $\begin{array}{c}\text { Intervention group } \\
(\mathrm{n}=10)\end{array}$ & $p$ valor \\
\hline Sex & 7 & 8 & 0.31 \\
\hline Male & 3 & 2 & \\
\hline Female & $39.5 \pm 17.63$ & $42.5 \pm 13.53$ & 0.34 \\
\hline $\begin{array}{l}\text { Age (mean } \pm \text { standard } \\
\text { deviation) }\end{array}$ & & & 0.5 \\
\hline $\begin{array}{l}\text { Location of pleural } \\
\text { effusion }\end{array}$ & & 5 & \\
\hline Right & 6 & 5 & 0.31 \\
\hline Left & 1 & 0 & \\
\hline Bilateral & & & \\
\hline $\begin{array}{l}\text { TB diagnosis } \\
\text { Positive culture for M }\end{array}$ & 2 & 3 & 0.33 \\
tb (pleural fragment) & & 7 & \\
\hline $\begin{array}{l}\text { Histopathologic } \\
\text { finding of granuloma } \\
\text { (pleural fragment) }\end{array}$ & 8 & 5 & \\
\hline Sites of disease & & & \\
\hline $\begin{array}{l}\text { Pleura } \\
\text { Lung + Pleura }\end{array}$ & 6 & & \\
\hline
\end{tabular}

Table 2. Pleural effusion volume and Modified Borg Scale rating before and after four weeks of treatment in the control group and in the intervention group.

\begin{tabular}{lccr}
\hline & $\begin{array}{c}\text { Control group } \\
(\mathrm{n}=10)\end{array}$ & $\begin{array}{c}\text { Intervention group } \\
(\mathrm{n}=10)\end{array}$ & $p$ value \\
\hline Volume $(\mathrm{mL})$ & & & \\
\hline Initial & $275.4(73.8-1360.8)$ & $401.9(97.6-1503.4)$ & 0.35 \\
\hline Final & $170.6(49.6-801.1)$ & $50.9(19.6-271.6)$ & 0.01 \\
\hline Relative variation (\%) & $36.9 \pm 2.9$ & $83.5 \pm 3.6$ & 0.001 \\
\hline Modified Borg Scale & & & \\
\hline Initial & $2.5(1-4)$ & $3.0(1-4)$ & 0.39 \\
\hline Final & $2.0(0-2)$ & $0(0-1)$ & 0.002 \\
\hline
\end{tabular}

*Data presented as mean \pm standard deviation (SD) or median. 


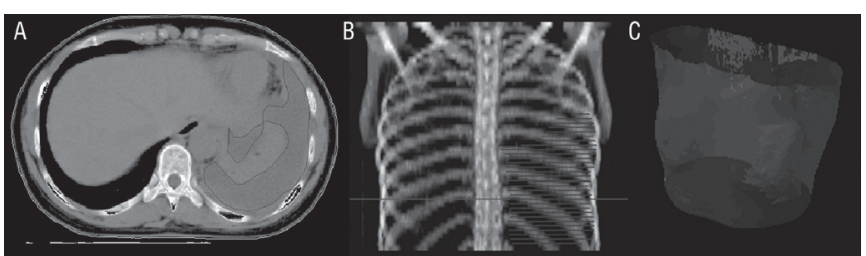

Figure 1. Reconstruction in three-dimensional (3D) imaging. A) Manual marking of pleural effusion. B) Evaluation of pleural effusion volume through volumetric analysis. C) Reconstruction in 3D imaging.

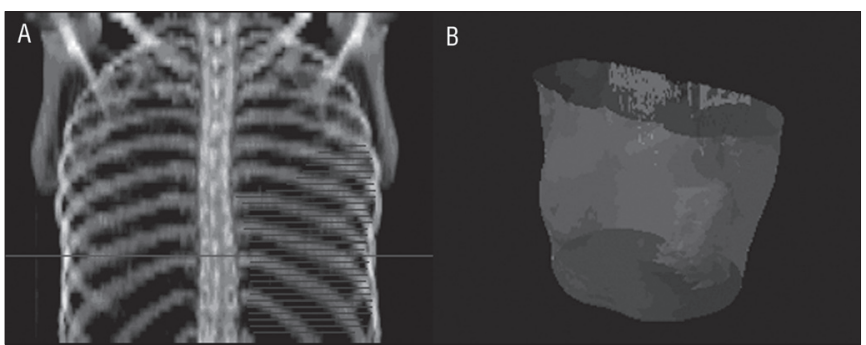

Figure 2. 3D reconstruction of the initial pleural effusion volume of an intervention group patient. A) Evaluation of pleural effusion volume through volumetric analysis. B) Reconstruction in 3D imaging.

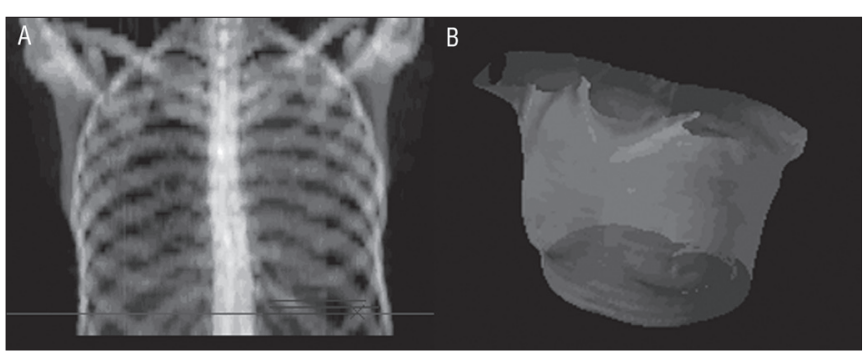

Figure 3. 3D reconstruction of the final pleural effusion volume of an intervention group patient. A) Evaluation of pleural effusion volume through volumetric analysis. B) Reconstruction in 3D imaging.

effusion due to TB is not part of the standard treatment, it has been reported by some authors that increasing the speed of fluid absorption decreased pleural thickening ${ }^{9,10,16}$. Vandevenne et al. ${ }^{17}$ associated respiratory physical therapy as an adjuvant in the treatment of residual pleural TB effusion after thoracocentesis. Thirteen patients did diaphragm exercises in addition to pharmacological treatment twice a day, for two weeks. This considerably improved the ventilation on the side with pleural effusion as well as respiratory volume, measured by 133 xenon $\left(\mathrm{Xe}^{133}\right)$ inhalation-perfusion scintigraphy.

As anti-TB drug therapy is the appropriate approach for treating pleural $\mathrm{TB}^{18}$, the inclusion of $\mathrm{CPAP}$ at the beginning of treatment might be helpful, mainly to those patients in which pleural effusion is causing respiratory discomfort. Although CPAP is normally considered a hospital-based, high technology intervention, its use requires low-cost equipment. Moreover, CPAP is broadly available in outpatient health care

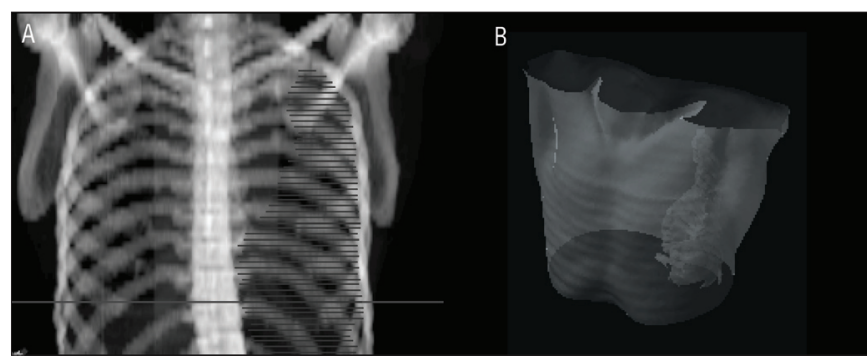

Figure 4. 3D reconstruction of the initial pleural effusion volume of a control group patient. A) Evaluation of pleural effusion volume through volumetric analysis. B) Reconstruction in 3D imaging.

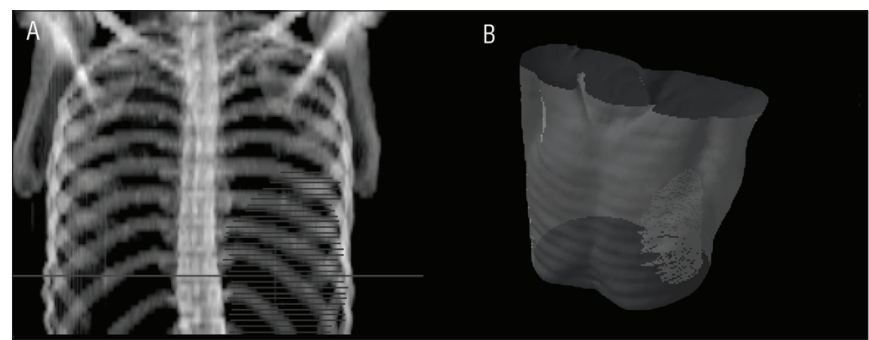

Figure 5. 3D reconstruction of the final pleural effusion volume of a control group patient. A) Evaluation of pleural effusion volume through volumetric analysis. B) Reconstruction in 3D imaging.

units and in home care environments, as well as in hospitals ${ }^{19}$. Additional evaluation is necessary in order to demonstrate its cost-effectiveness. Furthermore, complications associated with the use of non-invasive positive pressure are uncommon. Clinically significant gastric inflation is rare at a pressure of less than $30 \mathrm{cmH}_{2} \mathrm{O}$, and aspiration of gastric contents has a very low incidence ( $5 \%$ or less). Local complications such as skin abrasions - due to the contact with the mask - and conjunctivitis are more common (incidence of $15 \%$ ), yet potentially avoidable and easily treatable ${ }^{20-23}$. In the present study no adverse effects of CPAP were observed, however this may be due to the small sample size.

We used thoracic $\mathrm{CT}$ with $3 \mathrm{D}$ reconstruction to address several questions regarding the accuracy and precision of thoracic radiography ${ }^{24,25}$ and ultrasonography ${ }^{26}$ in the measurement of pleural effusion volume. For this reason, a workstation was utilized, as it is necessary for the transformation of the axial image into a volumetric image. This has been considered the gold standard for the evaluation of pleural effusion volume ${ }^{27-30}$.

A possible study limitation is the fact that TB treatment was not administered under Direct Observed Treatment Short Course (DOTS) strategy ${ }^{31,32}$. However, as both groups were monitored regarding drug ingestion and as they did not present with well known risk factors for treatment default (addiction to drugs, street dwelling, psychiatric disease, previous anti-TB treatment default), this fact likely did not influence our 
results. Moreover, an exclusion criterion was the interruption of anti-TB medication for more than 2 days.

Despite the small sample size, it was possible to demonstrate a significant effect of CPAP on the reduction of TB-related pleural effusion volume in the first four weeks of anti-TB treatment. However, further studies with larger sample sizes are necessary to further investigate a few issues, such as the patient's tolerance to the procedure, adverse effects of CPAP and implications of rapid involution of pleural effusion on quality of life. Thoracic image evaluation is also needed at the end of the six months of treatment and twelve months after the diagnosis in order to evaluate the impact of CPAP on reducing pleural sequelae. In conclusion, our findings suggest that the addition of CPAP to standard TB therapy during the initial phase of treatment is associated with accelerated fluid absorption in patients with pleural TB.

\section{References $: \because$.}

1. World Health Organization [homepage na internet]. Global tuberculosis control: surveillance, planning, financing. Geneva: World Health Organization (WHO); [atualizada em 2004; acesso em 13 Mar 2006]. Disponível em: http://www.who.int/tb/publications/globalreport/2004.

2. Ministerio da Saúde [homepage na internet]. Secretaria de Vigilância em Saúde.Brasília: Ministério da Saúde; [atualizada em 2004; acesso em Jun 2006]. Disponível em: http://portal.saude.gov.br/portal/saude/Gestor/ area.cfm?id_area=1498.

3. Seiscento M, Conde MB, Dalcolmo MMP. Tuberculose pleural. J Bras Pneumol. 2006;32(4):174-81.

4. Conde MB, Loivos AC, Rezende VM, Soares SL, Mello FC, Reingold AL, et al. Yield of sputum induction in the diagnosis of pleural tuberculosis. Am J Respir Crit Care Med. 2003;167(5):723-5.

5. Epstein DM, Kline LR, Albelda SM, Miller WT. Tuberculous pleural effusions. Chest. 1997;91(1):106-9.

6. Pérez JMP, CabaleeroMR. Secuelas del derrame pleural tuberculoso. Med Clin. 2005;124(13):494-6.

7. Candela A, Andujar J, Hernandez L, Martin C, Barroso E, Arriero JM, et al. Functional sequelae of tuberculous pleurisy in patients correctly treated. Chest. 2003;123(6):1996-2000.

8. Light RW. Pleural effusion. N Engl J Med. 2002;346(25):1971-7.

9. Ferrer J. Pleural tuberculosis. Eur Respir J. 1997;10(4):942-7.

10. Valdes L, Pose A, San José E, Martinez Vázquez JM. Tuberculous pleural effusions. Eur J Intern Med. 2003;14:77-88.

11. Borg GA. Psychophysical bases of perceived exertion. Med Sci Sports Exerc. 1982;14(5):377-81.

12. Breiman RS, Beck JW, Korobkin M, Glenny R, Akwari OE, Heaston DK, et al. Volume determinations using tomography. AJR Am J Roentgenol. 1982;138:329-33.

13. Barbas CS, Cukier A, de Varvalho CR, Barbas Filho JV, Light RW. The relationship between pleural fluid findings and the development of pleural thickening in patients with pleural tuberculosis. Chest. 1991;100(5):1264-7.

14. Chung $\mathrm{CL}$, Chen $\mathrm{CH}$, Yeh CY, Sheu JR, Chang SC. Early effective drainage in the treatment of loculated tuberculous pleurisy. Eur Respir J. 2008;31(6):1261-7.
15. Zhou A, Guo L, Tang L. Effect of an intrathoracic injection of sodium hyaluronic acid on the prevention of pleural thickening in excess fluid of tuberculous thoracic cavity. Clin Exp Pharmacol Physiol. 2003;30(3):203-5.

16. Valdes L, Alvarez D, San Jose E, Penela P, Valle JM, Garcia-Pazos JM. Tuberculous pleurisy: a study of 254 cases. Arch Intern Med. 1998;158:2017-21

17. Vandevenne A, Moyses B, Weitzenblum E, Carloz I, Methlin G. Regional pulmonary function in unilateral sero-fibrinous pleural effusions and changes under the influence of treatment. Poumon Coeur. 1981;37(3):223-8.

18. Sociedade Brasileira de Pneumologia e Tisiologia. II Consenso Brasileiro de Tuberculose: Diretrizes Brasileiras para Tuberculose 2004. J Bras Pneumol. 2004;30(Suppl 1):S24-38.

19. Leger P, Jennequin J, Gerard M, Robert D. Home positive pressure ventilation via nasal masks in patients with neuromuscular weakness and restrictive lung ou chest wall disease. Respir Care. 1989;34:73-9.

20. Hill NS. Complications of noninvasive positive pressure ventilation. Respir Care. 1997;42:432-42.

21. Richards GN, Cistulli PA, Ungar RG, Berthon-Jones M, Sullivan CE. Mouth leak with nasal continuous positive airway pressure increases nasal airway resistance. Am J Respir Crit Care Med. 1996;154(1): 182-6.

22. Janssens JP, Kehrer P, Chevrolet JC, Rocha T. Ventilation non-invasive (VNI) à domicile: suivi à long terme de 32 cases. Rev Mal Respir. 1999;16(4):511-20.

23. Mehta S, Hill NS. Noinvasive ventilation. Am J Respir Crit Care Med 2001;163(2):540-77.

24. Eibenberger KL, Dock WI, Ammann ME, Dorffner R, Hörmann MF, Grabenwoger F. Quantification of pleural effusion sonography versus radiograph. Radiology. 1994;191(3):681-4.

25. Roch A, Bojan M, Michelet P, Romain F, Bregeon F, Papazian L, et al Usefulness of ultrasonografhy in predicting pleural effusion $>500 \mathrm{ml}$ in patients receiving mechanical ventilation. Chest. 2005;127(9):224-32.

26. Vignon P, Chastagner C, Berkane V, Chardac E, François B, Normand $S$, et al. Quantitative assessment of pleural effusion in critically ill patients by means of ultrasonography. Crit Care Med. 2005;33(8): 1757-63. 
27. Hulnick DH, Naidich DP, Mccauley DI. Pleural tuberculosis evaluated by computed tomography. Radiology. 1983;149(3):759-65.

28. Choi JA, Hong KT, Chung YM, Seol HY, Kang EY. CT manifestations of late sequelae in patients with tuberculous pleuritis. AJR AM J Roentgenol. 2001;176(2):441-5.

29. Gebrin EMMS. Incorporação de novas tecnologias em tomografia computadorizada. Radiol Bras. 2004;37(1):III-IV.
30. Diaz-Guzman E, Budey MM. Accuracy of the physical examination in evaluating pleural effusion. Cleve Clin J Med. 2008;75(4):297-303.

31. World Health Organization. An expanded DOTS framework for effective tuberculosis control: stop TB comunicable disease. Geneva: World Health Organization; 2002.

32. World Health Organization. Global tuberculosis control: surveillance, planning, financing. Geneva: World Health Organization; 2005. 